\title{
Intemperismo Artificial em Lâminas de Tectona grandis Tratadas com Produtos de Acabamento
}

\author{
Francis Lívio Corrêa Queiroz ${ }^{1}$, Joaquim Carlos Gonçalez ${ }^{1}$, \\ Cláudio Henrique del Menezzi ${ }^{1}$, Edilene Silva Ribeiro ${ }^{1}$, Clarissa Melo Lima ${ }^{1}$ \\ ${ }^{1}$ Departamento de Engenharia Florestal, Universidade de Brasília - UnB, Brasília/DF, Brasil
}

\begin{abstract}
RESUMO
Este estudo teve por objetivo avaliar a ação do tempo de exposição ao intemperismo artificial na cor de lâminas de madeiras de teca tratadas com produtos de acabamento. Amostras que receberam 2 tipos de produto, a seladora e o stain, mais as testemunhas, sem acabamento. $\mathrm{O}$ experimento foi instalado no delineamento inteiramente casualizado, com 3 tratamentos e 4 repetições. As lâminas ficaram expostas ao simulador QUV-Acelerated Weathering Teste, por 7 períodos, de: 6, 12, 24, 48, 96, 192 e 384 horas. Após cada período de intemperismo foram feitas medições das cores, com espectrofotômetro COLOR EYe XTH. As variáveis cromáticas avaliadas foram: $\mathrm{L}^{\star}, \mathrm{a}^{*}, \mathrm{~b}^{*}, \mathrm{C}$ e $\mathrm{h}^{*}$. Ao final do estudo pôde-se concluir que as lâminas de madeira de teca sofreram alterações em sua cor com o passar do tempo de exposição e que o stain apresentou maior eficiência na conservação da cor da madeira.
\end{abstract}

Palavras-chave: teca, fotodegradação, colorimetria, seladora, stain.

\section{Artificial Weathering in Tectona grandis Slides Treated with Finishing Products}

\begin{abstract}
This study aims to evaluate the effects of weather exposure to artificial weathering in the color of teak wood veneer treated with finishing products. The samples received 2 types of products, the sealer and the stain, plus witnesses, unfinished. The experiment was conducted in a completely randomized design with 3 treatments and 4 replications. Slides were exposed to QUV-Accelerated Weathering Test simulator for 7 periods as follow: 6, 12, 24, 48, 96, 192 and 384 hours. Color measurements were made after each period of weathering using the spectrophotometer Color Eye XTH. The chromatic variables evaluated were: $\mathrm{L}^{*}, \mathrm{a}^{*}, \mathrm{~b}^{*}, \mathrm{C}^{*}$ and $\mathrm{h}^{*}$. The study concluded that the teak wood veneer had color alterations with the exposure time and the stain was more efficient in preserving the wood color.
\end{abstract}

Keywords: teak, photobleaching, colorimetry, sealer, stain. 


\section{INTRODUÇÃO}

As indústrias madeireiras, no Brasil, utilizam em grande escala toras de árvores do gênero Pinus e Eucalyptus para processamento mecânico. Entretanto, o reflorestamento com Tectona grandis (teca) surge como uma boa alternativa de investimento (Lima et al., 2011). Teca, segundo ABRAF (2013), é plantada principalmente nos estados do Mato Grosso e do Pará, cobrindo cerca de 68 mil hectares de reflorestamento no Brasil.

Conforme Thulasidas et al. (2006), a madeira da teca é considerada premium, valorizada pela sua atratividade, com cor amarela ou marrom dourada. Entre outras propriedades desejáveis dessa madeira incluem-se durabilidade natural, bem como facilidade na usinagem e no acabamento. Porém, a despeito da sua importância econômica e da ampla utilização da espécie, carência de informações sobre diversos aspectos (Costa et al., 2009), sobretudo quanto à qualidade dessa madeira, ainda persiste.

Para Camargos \& Gonçalez (2001), de maneira geral a cor da madeira é muito instável, estando sujeita a alterações rápidas, sendo que tal instabilidade se encontra intrinsecamente relacionada com os elementos anatômicos e constituintes da madeira. Tal propriedade da madeira pode ser alterada pelo intemperismo, que é uma ação complexa e combinada de sol, chuva ou umidade e vento (Hon, 2001 apud Pastore, 2004). Essas alterações ocorrem principalmente devido à ação dos raios ultravioleta, que provocam tanto a fotodegradação quanto a fotodescoloração da madeira, diminuindo sua vida útil (Gouveia, 2008). Por essa razão, produtos de acabamento como vernizes, stains e tintas são usados para proteger a superfície da madeira, amenizando a degradação.

A madeira de Tectona grandis processada e acabada tem sido objeto de estudos da relação da cor e acabamento em função da deterioração produzida pela exposição à intempérie. A propriedade da cor da madeira associada a técnicas de acabamento é objeto de estudo de Lopes et al. (2014), que buscaram a uniformização da cor da madeira de árvores jovens, peças de cerne e alburno, pela aplicação de tratamento termorretificador, a fim de tornar a madeira maciça mais interessante para o consumo.

Devido à crescente importância da madeira de Tectona grandis no Brasil, conhecer a sua cor e a variação dela em função de produtos de acabamento empregados na madeira e do tempo da sua exposição à intempérie é fundamental para o uso maximizado desse produto florestal. Assim, este trabalho teve por objetivo avaliar a ação do tempo de exposição ao intemperismo artificial na cor de lâminas de madeira de Tectona grandis tratadas com produtos de acabamento.

\section{MATERIAL E MÉTODOS}

A avaliação da cor das lâminas de teca em função do intemperismo acelerado foi realizada no laboratório de tecnologia da madeira do Departamento de Engenharia Florestal da Faculdade de Tecnologia da UnB.

As amostras de Tectona grandis, em lâminas, provieram de povoamento florestal com 13 anos de idade, instalado no município de Juara, estado de Mato Grosso. As lâminas com corte contínuo em torno rotativo, foram torneadas na mesma unidade produtora das árvores, de propriedade de Sharewood Reflorestadora do Brasil Ltda. Essas lâminas foram transformadas em amostras de dimensão $9,5 \mathrm{~cm}$ de comprimento $\times 6,5 \mathrm{~cm}$ de largura $\times 0,12 \mathrm{~cm}$ de espessura.

As amostras receberam dois tipos de acabamento, seladora e stain. Mais as testemunhas, sem acabamento. Em delineamento inteiramente casualisado (DIC), o experimento configurou-se em 3 tratamentos em 4 repetições, totalizando 12 unidades amostrais. A seladora utilizada foi a NL 9245-00; o stain aplicado foi o Semitransparente - Natural UV Gold - Código: 33b080101. Composição: 3 iodo, 2 propinil-butil carbamato (IPBC) - 0,25\%; inertes (resinas, óleos vegetais, pigmentos inorgânicos, cargas minerais, solventes alifáticos e aromáticos derivados de petróleo) $-99,75 \%$.

Todas as amostras foram lixadas com lixa grana 280 para madeira e em seguida tratadas, recebendo duas demãos por pincel de cerdas com os produtos de acabamento, sendo: 4 amostras tratadas com seladora; 4 amostras tratadas com stain; e mais 4 amostras no estado natural, testemunhas (sem acabamento).

\subsection{Acelerador de intemperismo}

A máquina simuladora de intemperismo acelerado usada no ensaio foi a QUV-Acelerated Weathering Teste - Q-LAB Modelo QUV/SPRAY - U2061-L. Que é uma câmara que reproduz testes de intemperismo, 
ou seja, os danos causados pela chuva, orvalho e luz solar sobre os materiais. Para isso, as lâminas foram submetidas a ciclos alternados de umidade, utilizando-se spray de água para imitar chuva, evaporação de água sob temperaturas elevadas, reproduzindo o orvalho. A luz ultravioleta da câmara, produzida por lâmpadas especiais de UV fluorescente, reproduz os danos causados pela luz solar.

As lâminas ficaram expostas ao simulador de intemperismo por 7 períodos, sendo: $6,12,24,48$, 96, 192 e 384 horas. Totalizando 756 horas de teste.

O ensaio observou metodologia conforme com a norma ASTM G 154 de 2006. G 157 (ASTM, 2006), períodos 7 , em ciclos, com as seguintes fases e parâmetros: 1 - UV - exposição a luz por 8 horas, de lâmpadas tipo UVA 340, com comprimento de onda de $340 \mathrm{~nm}$, produzindo irradiação de $1,55 \mathrm{~W} / \mathrm{m}^{2}$ e temperatura de $60^{\circ} \mathrm{C} ; 2$ - spray - exposição a água por 0,25 horas, sem luz e sem controle de temperatura interna da câmara; e 3 - condensação - por 3,75 horas, com temperatura de $50^{\circ} \mathrm{C}$ e sem luz. Cada ciclo de intemperismo, com as 3 fases, possui 12 horas.

\subsection{Colorimetria}

O aparelho utilizado para medir as cores das lâminas da madeira após cada período de intemperismo foi o espectrofotômetro portátil COLOR EYe XTH - GretagMacbeth, de refletância difusa no intervalo visível do espectro eletromagnético, com iluminante D65 e com ângulo de $10^{\circ}$. As variáveis cromáticas avaliadas foram: $\mathrm{L}^{*}, \mathrm{a}^{*}, \mathrm{~b}^{*}, \mathrm{C}$ e $\mathrm{h}^{*}$, do sistema CIE $1976 L^{*} a^{\star} b^{\star}$ (CIELAB), (CIE, 1976), com 20 leituras para cada amostra, no plano tangencial, para cada período, somando 1.680 leituras. Mais 240 leituras na primeira avaliação com as amostras sem nenhum acabamento, antes do início dos períodos, totalizando 1.920 registros.

O espectrofotômetro foi acoplado a um computador que, com o software Color iControl, processou automaticamente os dados do fluxo de radiação.

Para a mensuração da alteração de cor nas amostras, combinando as variáveis $\mathrm{L}^{*}, \mathrm{a}^{*}$ e $\mathrm{b}^{*}$, antes e depois das exposições $(\Delta \mathrm{E})$, foi utilizada a fórmula da Equação 1 . Para verificar a variação total da cor $(\Delta \mathrm{E})$ em cada tratamento, utilizou-se a Tabela 1 (Hikita et al., 2001 apud Lima et al., 2013).
Tabela 1. Classificação da variação total da cor $(\Delta \mathrm{E})$ de madeiras.

Table 1. Rating of the total variation of color $(\Delta \mathrm{E})$ of woods.

\begin{tabular}{cl}
\hline VARIAÇÃO TOTAL DA & \multicolumn{1}{c}{ CLASSIFICAÇÃO } \\
COR $(\boldsymbol{\Delta E})$ & Desprezível \\
\hline $0,0-0,5$ & Ligeiramente perceptível \\
$0,5-1,5$ & Notável \\
\hline $1,5-3,0$ & Apreciável \\
$3,0-6,0$ & Muito apreciável \\
\hline $6,0-12,0$ & \\
\hline
\end{tabular}

$\Delta \mathrm{E}=\sqrt{\Delta \mathrm{L}^{2}+\Delta \mathrm{a}^{2}+\Delta \mathrm{b}^{2}}$

Com os valores da classificação da variação total da cor entre os períodos de intemperismo aplicados aos tratamentos foi possível quantificar o quanto os produtos utilizados no acabamento interferiram na mudança de cor da madeira de teca em uso externo.

\subsection{Processamento de dados das cores das lâminas}

Os dados obtidos de saturação (C), ângulo da cor $\left(h^{*}\right)$, claridade $\left(L^{*}\right)$ e matiz $\left(a^{*}\right.$ e $\left.b^{*}\right)$ passaram por análise de variância, teste $\mathrm{F}$, com de significância de $\rho<0,05$, e por teste de médias de Tukey $(\rho<0,05)$, pelo sistema computacional SAEG, nos casos em que houve rejeição da hipótese nula $(\mathrm{H}: \mu \neq 0)$.

\section{RESULTADOS E DISCUSSÃO}

Como descreveu Gonzaga (2006), no corte tangenciando e seccionando, os anéis produzem desenhos na face da madeira, formados pelos cones seccionados de crescimento do tronco da árvore, elemento de decoração muito apreciado pelo consumidor. Para a madeira de teca, o seccionamento em posição tangencial produz lâminas com coloração desuniforme, com diferenças de cor e nuances em função da concentração de extrativos entre os anéis. $\mathrm{O}$ estudo de intemperismo foi desenvolvido em amostras que apresentavam a sua face tangencial marcada por essa heterogeneidade de cor.

Os valores médios das variáveis cromáticas ( $\mathrm{L}^{*}, \mathrm{a}^{*}$, $\mathrm{b}^{*}, \mathrm{C} \mathrm{e} \mathrm{h}^{*}$ ) avaliadas nas lâminas de Tectona grandis, para cada período, em função dos tratamentos, são apresentados na Tabela 2. 
Tabela 2. Valores médios dos parâmetros colorimétricos $\left(\mathrm{L}^{*}, \mathrm{a}^{*}, \mathrm{~b}^{*}, \mathrm{C}\right.$ e $\left.\mathrm{h}^{*}\right)$ de lâminas de Tectona grandis para cada período, em função de tratamentos, seladora, stain e testemunhas.

Table 2. Average values of the colorimetric parameters $\left(\mathrm{L}^{*}, \mathrm{a}^{*}, \mathrm{~b}{ }^{*}, \mathrm{C}\right.$ and $\left.\mathrm{h}^{\star}\right)$ Tectona grandis veneer for each period, depending on the treatments, sealer, stain and control.

\begin{tabular}{|c|c|c|c|c|c|c|c|}
\hline \multirow{2}{*}{ Tratamento } & \multirow{2}{*}{$\begin{array}{c}\text { Período } \\
\text { (h) }\end{array}$} & \multicolumn{5}{|c|}{ Parâmetros colorimétricos } & \multirow{2}{*}{ Cor } \\
\hline & & $\mathbf{L}^{\star}$ & $a^{\star}$ & $\mathbf{b}^{\star}$ & C & $\mathbf{h}^{\star}$ & \\
\hline Testemunhas & $0^{1}$ & $51,22 \mathrm{a}$ & $11,14 \mathrm{c}$ & $25,87 b$ & $28,17 \mathrm{~b}$ & $65,88 \mathrm{a}$ & Marrom-oliva \\
\hline Seladora & $0^{1}$ & $52,64 b$ & $11,64 a$ & $26,89 a$ & $29,31 \mathrm{a}$ & $66,62 \mathrm{a}$ & Marrom-oliva \\
\hline Stain & $0^{1}$ & $53,59 \mathrm{a}$ & $11,47 \mathrm{a}$ & $26,42 b$ & $28,80 \mathrm{~b}$ & $66,51 \mathrm{a}$ & Marrom-oliva \\
\hline Testemunhas & 6 & $53,35 \mathrm{a}$ & $10,89 \mathrm{c}$ & $28,51 \mathrm{a}$ & $30,52 \mathrm{a}$ & $69,08 \mathrm{a}$ & Amarelo amarronzado \\
\hline Seladora & 6 & $43,37 b$ & $14,36 b$ & $26,06 b$ & $29,76 \mathrm{~b}$ & $61,11 \mathrm{~b}$ & Amarelo amarronzado \\
\hline Stain & 6 & $41,81 \mathrm{c}$ & $15,80 \mathrm{a}$ & $25,22 \mathrm{c}$ & $29,77 b$ & $57,82 \mathrm{c}$ & Amarelo amarronzado \\
\hline Testemunhas & 12 & $43,10 \mathrm{a}$ & $13,85 b$ & $28,49 \mathrm{a}$ & $31,70 \mathrm{a}$ & $64,00 \mathrm{a}$ & Amarelo amarronzado \\
\hline Seladora & 12 & $42,26 a$ & $13,34 b$ & $21,13 b$ & $25,02 \mathrm{c}$ & $57,47 b$ & Marrom avermelhado \\
\hline Stain & 12 & $38,77 b$ & $14,43 a$ & $22,10 \mathrm{~b}$ & $26,41 b$ & $56,52 \mathrm{c}$ & Marrom avermelhado \\
\hline Testemunhas & 24 & - & $14,96 b$ & $24,77 \mathrm{a}$ & $28,98 \mathrm{a}$ & $58,55 \mathrm{a}$ & Marrom avermelhado \\
\hline Seladora & 24 & $40,52 \mathrm{a}$ & $15,49 \mathrm{a}$ & $23,32 b$ & $28,01 \mathrm{a}$ & $56,34 \mathrm{c}$ & Marrom avermelhado \\
\hline Stain & 24 & $40,84 a$ & $15,36 \mathrm{a}$ & $24,26 \mathrm{ab}$ & $28,72 a$ & $57,51 \mathrm{~b}$ & Marrom avermelhado \\
\hline Testemunhas & 48 & $50,64 \mathrm{a}$ & $13,46 \mathrm{c}$ & $30,60 \mathrm{a}$ & $33,43 a$ & $66,25 \mathrm{a}$ & Marrom-oliva \\
\hline Seladora & 48 & $40,02 \mathrm{c}$ & $16,68 \mathrm{a}$ & $24,31 b$ & $29,49 b$ & $55,51 \mathrm{c}$ & Marrom avermelhado \\
\hline Stain & 48 & $40,94 b$ & $15,15 b$ & $24,05 b$ & $28,45 \mathrm{c}$ & $57,56 \mathrm{~b}$ & Marrom avermelhado \\
\hline Testemunhas & 96 & $51,70 \mathrm{a}$ & $12,57 \mathrm{c}$ & $28,95 \mathrm{a}$ & $31,57 \mathrm{a}$ & $66,51 \mathrm{a}$ & Marrom-oliva \\
\hline Seladora & 96 & $40,39 c$ & $17,18 \mathrm{a}$ & $25,03 \mathrm{c}$ & $30,37 b$ & $55,45 \mathrm{c}$ & Amarelo amarronzado \\
\hline Stain & 96 & $43,16 b$ & $15,46 b$ & $25,99 \mathrm{~b}$ & $30,26 \mathrm{~b}$ & $59,07 \mathrm{~b}$ & Amarelo amarronzado \\
\hline Testemunhas & 192 & $56,91 \mathrm{a}$ & $10,57 \mathrm{c}$ & $25,82 \mathrm{~b}$ & $27,91 \mathrm{c}$ & $67,75 \mathrm{a}$ & Amarelo amarronzado \\
\hline Seladora & 192 & $43,54 \mathrm{c}$ & $17,71 \mathrm{a}$ & $28,02 \mathrm{a}$ & $33,19 a$ & $57,57 \mathrm{c}$ & Amarelo amarronzado \\
\hline Stain & 192 & $44,86 b$ & $14,72 b$ & $26,30 \mathrm{~b}$ & $30,16 \mathrm{~b}$ & $60,66 \mathrm{~b}$ & Amarelo amarronzado \\
\hline Testemunhas & 384 & $60,09 a$ & $08,50 \mathrm{c}$ & $21,57 \mathrm{c}$ & $23,19 \mathrm{c}$ & $68,53 \mathrm{a}$ & Oliva amarelado \\
\hline Seladora & 384 & $53,57 \mathrm{~b}$ & $13,93 \mathrm{a}$ & $29,93 \mathrm{a}$ & $33,05 \mathrm{a}$ & $65,14 \mathrm{~b}$ & Amarelo amarronzado \\
\hline Stain & 384 & $48,55 \mathrm{c}$ & $12,75 b$ & $27,95 b$ & $30,75 b$ & $65,39 \mathrm{~b}$ & Marrom-oliva \\
\hline
\end{tabular}

$0^{1}=$ Leitura antes dos períodos de intemperismo; Médias seguidas pela mesma letra na coluna, por período de intemperismo, não diferem estatisticamente entre si pelo teste de Tukey a 5\% de probabilidade.

Analisando-se essa tabela e os tratamentos antes dos períodos de intemperismo $\left(0^{1}\right)$, a cor natural da lâmina de madeira de teca é marrom-oliva, caracterizada pelos parâmetros colorimétricos médios das amostras testemunhas: $\mathrm{L}^{\star}(51,22), \mathrm{a}^{*}(11,14), \mathrm{b}^{*}(25,87), \mathrm{C}$ $(28,17) \mathrm{eh}^{\star}(65,88)$. Apesar de a coordenada $\mathrm{b}^{\star}$ ter uma participação marcante na formação da cor final dessa espécie, percebe-se também a influência significativa da coordenada $\mathrm{a}^{\star}$. A participação desses dois pigmentos (amarelo e vermelho) em proporções diferentes culmina na cor da espécie (marrom-oliva). As amostras que receberam os produtos de acabamento (seladora e stain) não sofreram alterações de sua cor natural, apesar de os valores da claridade $\left(L^{*}\right)$ mostrarem diferenças estatísticas em relação às testemunhas. A classificação utilizada para a definição da cor (Camargos \& Gonçalez, 2001) é baseada na análise de cluster, que agrupa valores de variáveis com afinidade para definição do grupo de cores. Essas variáveis possuem intervalos de valores mais elásticos, incluindo valores próximos em um mesmo grupo, como foi o caso dos três tratamentos antes dos períodos de intemperismo. No caso de se querer realizar uma triagem mais fina (peças de um lote mais homogêneo de cor), através dos parâmetros colorimétricos, a ANOVA seguida do teste de Tukey consegue fazer essa separação.

Com o arranjo das variáveis cromáticas foi possível obter 4 grupos de cores, conforme classificação de Camargos \& Gonçalez (2001): marrom-oliva, grupo de cores 13; oliva amarelado, grupo de cores 18; amarelo amarronzado, grupo de cores 23 e marrom avermelhado, grupo de cores 25. As lâminas dos três tratamentos antes dos períodos de intemperismo enquadraram-se no grupo 13, marrom-oliva.

As lâminas testemunhas foram as que apresentaram maior variação de cor em função dos períodos 
de intemperismo. Variaram de marrom-oliva, até 6 horas, passando para marrom avermelhado, entre 12 e 36 horas. Entre 36 e 180 horas enquadraram-se entre as cores amarelo amarronzado e marrom-oliva. E, finalmente, às 756 horas, sob intemperismo acelerado, enquadraram-se na cor oliva amarelado. Os valores de $L^{*}$ (claridade) das testemunhas diminuíram até o tratamento de 48 horas, e os da coordenada a ${ }^{*}$ (vermelho), aumentaram, justificando o escurecimento da madeira com o passar do tempo. A partir do tratamento de 96 horas, a cor da madeira das testemunhas voltaram a clarear, mostrando um valor de $\mathrm{L}^{\star}$ de 60,09 no tratamento de 384 horas, mais clara mesmo do que antes dos períodos de tratamentos, passando a madeira para a cor oliva amarelado. Tanto o valor de $\mathrm{a}^{\star}$ como o de $b^{*}$ diminuíram, deixando a madeira mais clara. O intemperismo para as testemunhas levou a um desbotamento da cor da madeira, deixando-a com um aspecto desgastado.

Durante a aplicação dos períodos de intemperismo, as cores das lâminas acabadas com seladora variaram de marrom-oliva, até 12 horas, a marrom avermelhado (25), entre 12 e 84 horas, até a estabilização na cor amarelo amarronzado (23), após 84 horas de exposição. As cores das lâminas acabadas com stain, durante a aplicação dos períodos de intemperismo, variaram de amarelo marronzado, até 6 horas, a marrom avermelhado, entre 12 e 384 horas, estabilizando-se na cor marrom-oliva após 384 horas de exposição. Observa-se que os valores das coordenadas $\mathrm{a}^{*} \mathrm{e} \mathrm{b}^{*}$, ao final do último tratamento, tanto para seladora como para o stain, são maiores que para os tratamentos iniciais $\left(0^{1}\right)$. Isso demostra que esses produtos conseguiram proteger a madeira contra o intemperismo. A classificação da cor ao final do processo em amarelo amarronzado (seladora) e marrom-oliva (stain), deveu-se, principalmente, ao aumento de ambas as coordenadas $\left(\mathrm{a}^{*} \mathrm{e} \mathrm{b}^{*}\right)$, devido à presença desses produtos. Pode-se inferir que os pigmentos dos produtos de acabamento interagiram com os da madeira, levando ao aumento desses e à definição da cor final. Com relação à manutenção da cor original da madeira, o produto stain se mostrou mais eficiente.

Lopes (2012), usando tabela de grupo de cores de Camargos (1999), chegou à classificação da cor do cerne de madeira maciça de teca, sem tratamento, com 12 anos de idade, no grupo marrom-oliva, $\mathrm{a}^{\star}\left(8,65\right.$ a 9,19), $\mathrm{b}^{\star}$ (> 15) e $\mathrm{L}^{\star}(58,63$ a 60,23$)$. O alburno foi classificado no grupo branco-acinzentado, $a^{*}(5,15$ a 10,39$), b^{*}$ $(20,03$ a 22,09$)$ e $L^{*}(72,01$ a 75,80$)$.

Thulasidas et al. (2006), estudando a variação da cor do cerne de Tectona grandis originada de florestas plantadas e de florestas tropicais, tipo florestas inundadas, de Kerala, sul da Índia, concluiu que a cor da madeira de florestas inundadas é mais pálida (menor amarelecimento), o que é fator limitante de preço para uso em movelaria de casas e jardins, em comparação com a cor da madeira de florestas plantadas. Os resultados para a classificação das cores das lâminas antes dos períodos de intemperismo confirmam relato de Bryce (1966) de que a menor rotação de cultivo e o crescimento mais rápido da Tectona grandis são fatores que podem conferir uma cor mais pálida à madeira.

Conforme classificação de Camargos (1999), a cor das lâminas da madeira de teca, pela variável luminosidade $L^{*}$ entre 34,46 e 52,72 , é escura $\left(L^{*}<54\right)$, ficando clara $L^{*}$ igual a $54,07\left(L^{*}>54\right)$ apenas depois de 384 horas sob ação de intemperismo acelerado.

Lukmandaru (2011), buscando correlacionar conteúdo e propriedades de cor de extrativos de madeira de teca com propriedades de sua resistência natural a cupim, com as propriedades de cor, medidas pelo sistema CIELab, chegou a resultados que mostraram que a luminosidade $\left(\mathrm{L}^{*}\right)$ e a cor vermelha $\left(\mathrm{a}^{*}\right)$ variaram significativamente na direção radial em função do conteúdo dos extrativos.

A análise da variação total na cor da madeira $(\Delta \mathrm{E})$ e sua classificação, conforme Tabela 1, antes e após os tratamentos, são apresentados na Tabela 3, na qual os valores para as variáveis, quando positivos, indicam que as lâminas ficaram mais clara $\left(\Delta \mathrm{L}^{*}\right)$, vermelha $\left(\Delta \mathrm{a}^{*}\right)$ e amarela $\left(\Delta \mathrm{b}^{\star}\right)$, e quando negativos, que as lâminas ficaram mais escura $\left(-\Delta \mathrm{L}^{*}\right),\left(-\Delta \mathrm{a}^{*}\right)$ verde $\mathrm{e}\left(-\Delta \mathrm{a}^{*}\right)$ azul.

As lâminas com acabamento por seladora e stain, em função da exposição, foram classificadas como muito apreciáveis $(6,0$ a 12,0) no início dos períodos, com classificação decrescente. Ao final dos períodos, as lâminas tratadas com seladora foram classificadas como muito apreciáveis, enquanto as lâminas acabadas com stain foram classificadas como apreciáveis $(3,0$ a 6,0$)$. Essa classificação permite dizer que o produto stain conseguiu dar uma maior estabilidade à cor ao final do tempo de intemperismo estudado. Para as lâminas testemunhas, a variação total da cor no início dos períodos foi ligeiramente perceptível 
Tabela 3. Variação dos parâmetros colorimétricos em função dos produtos de acabamento e do tempo de exposição na câmara de intemperismo acelerado.

Table 3. Variation the colorimetric parameters in function of the finished product and the exposure time in the accelerated weathering chamber.

\begin{tabular}{|c|c|c|c|c|c|c|c|}
\hline \multirow{2}{*}{ Tratamento } & \multirow{2}{*}{$\begin{array}{c}\text { Período } \\
\text { (h) }\end{array}$} & \multirow{2}{*}{$\begin{array}{c}\text { Tempo de } \\
\text { exposição } \\
\text { (h) }\end{array}$} & \multicolumn{4}{|c|}{ Variação dos parâmetros colorimétricos } & \multirow{2}{*}{$\frac{\text { Classificação }}{\Delta \mathrm{E}}$} \\
\hline & & & $\Delta \mathbf{L}^{*}$ & $\Delta \mathbf{a}^{\star}$ & $\Delta \mathbf{b}^{*}$ & $\Delta \mathbf{E}$ & \\
\hline \multirow{8}{*}{ Testemunhas } & $0^{1}$ & $0^{1}$ & $-0,71$ & $-0,13$ & $-0,34$ & 0,80 & LP \\
\hline & 6 & 6 & $-1,42$ & 0,38 & $-2,3$ & 2,73 & $\mathrm{~N}$ \\
\hline & 12 & 12 & 10,25 & $-2,96$ & 0,02 & 10,67 & MA \\
\hline & 24 & 36 & 9,09 & $-1,11$ & 3,72 & 9,88 & MA \\
\hline & 48 & 84 & $-16,63$ & 1,5 & $-5,83$ & 17,69 & MA \\
\hline & 96 & 180 & $-1,06$ & 0,89 & 1,65 & 2,15 & $\mathrm{~N}$ \\
\hline & 192 & 372 & $-5,21$ & 2 & 3,13 & 6,40 & MA \\
\hline & 384 & 756 & $-3,18$ & 2,07 & 4,25 & 5,70 & A \\
\hline \multirow{8}{*}{ Seladora } & $0^{1}$ & $0^{1}$ & $-6,3$ & 2,28 & 0,53 & 6,72 & MA \\
\hline & 6 & 6 & 9,27 & $-2,72$ & 0,83 & 9,70 & MA \\
\hline & 12 & 12 & 1,11 & 1,02 & 4,93 & 5,15 & A \\
\hline & 24 & 36 & 1,74 & $-2,15$ & $-2,19$ & 3,53 & A \\
\hline & 48 & 84 & 0,5 & $-1,19$ & $-0,99$ & 1,63 & $\mathrm{~N}$ \\
\hline & 96 & 180 & $-0,37$ & $-0,5$ & $-0,72$ & 0,95 & LP \\
\hline & 192 & 372 & $-3,15$ & $-0,53$ & $-2,99$ & 4,37 & A \\
\hline & 384 & 756 & $-10,03$ & 3,78 & $-1,91$ & 10,89 & $\mathrm{~N}$ \\
\hline \multirow{8}{*}{ Stain } & $0^{1}$ & $0^{1}$ & $-10,87$ & 4,77 & 0,22 & 11,87 & MA \\
\hline & 6 & 6 & 11,78 & $-4,33$ & 1,2 & 12,61 & MA \\
\hline & 12 & 12 & 3,04 & 1,37 & 3,12 & 4,57 & A \\
\hline & 24 & 36 & $-2,07$ & $-0,93$ & $-2,16$ & 3,13 & A \\
\hline & 48 & 84 & $-0,1$ & 0,21 & 0,21 & 0,31 & $\mathrm{D}$ \\
\hline & 96 & 180 & $-2,22$ & $-0,31$ & $-1,94$ & 2,96 & $\mathrm{~N}$ \\
\hline & 192 & 372 & $-1,7$ & 0,74 & $-0,31$ & 1,88 & $\mathrm{~N}$ \\
\hline & 384 & 756 & $-3,69$ & 1,97 & $-1,65$ & 4,50 & A \\
\hline
\end{tabular}

$0^{1}=$ Leitura antes dos períodos de intemperismo; $\mathrm{D}=$ Desprezível; LP = Ligeiramente perceptível; $\mathrm{N}=$ Notável; $\mathrm{A}=$ Apreciável; $\mathrm{MA}$ = Muito apreciável.

$(0,5$ a 1,5$)$, chegando a muito apreciável $(6,0$ a 12,0$)$ com 84 horas de exposição, finalizando, às 756 horas de exposição, classificadas como apreciáveis $(3,0$ a 6,0$)$. Como já mencionado anteriormente, houve desgaste da cor da madeira, o qual afetou o valor da claridade $\left(L^{*}\right)$, levando a uma alteração da cor com relação às lâminas testemunhas iniciais, conferindo aspecto desbotado à madeira.

A variação dos parâmetros colorimétricos neste ensaio é o que melhor explica a alteração da cor em função do tempo de intemperismo para as lâminas com tratamento de acabamento em relação às testemunhas. Para as lâminas tratadas com seladora, a variável claridade teve comportamento de clareamento $\left(\Delta \mathrm{L}^{\star}\right)$ em função do intemperismo até 180 horas de exposição. A partir de 180 horas, as lâminas escureceram $\left(-\Delta \mathrm{L}^{\star}\right)$. Quanto à tonalidade, houve predominância das pigmentações verde $\left(-\Delta \mathrm{a}^{*}\right)$ e azul $\left(-\Delta \mathrm{b}^{*}\right)$. Nas lâminas tratadas com stain, a variável claridade, obtida foi predominantemente escura $\left(-\Delta \mathrm{L}^{*}\right)$. Quanto à tonalidade, houve predominância das pigmentações verde $\left(-\Delta \mathrm{a}^{*}\right)$ e azul $\left(-\Delta \mathrm{b}^{\star}\right)$. Nas lâminas sem tratamento, a variável claridade começou o período de intemperismo acelerado com as lâminas escuras $\left(-\Delta \mathrm{L}^{*}\right)$, clareando até 24 horas de teste $\left(\Delta \mathrm{L}^{\star}\right)$; após 48 horas de exposição, essas lâminas voltaram a escurecer $\left(-\Delta L^{*}\right)$. Já a tonalidade (C) das lâminas começou com as pigmentações verde $\left(-\Delta \mathrm{a}^{\star}\right)$ e azul $\left(-\Delta \mathrm{b}^{\star}\right)$ e, com o passar do tempo sob intemperismo, derivou para as pigmentações vermelha $\left(\Delta \mathrm{a}^{\star}\right)$ e amarela $\left(\Delta \mathrm{b}^{*}\right)$.

Teles (2014), em ensaio com madeiras amazônicas tratadas quimicamente, observou a mesma tendência de escurecimento das peças após intemperismo com elevação da luminosidade $\left(L^{*}\right)$ em função do aumento 
do tempo de exposição, sugerindo que esse resultado é função da lixiviação de constituintes da parede celular pela água na fase de spray.

Igualmente, o resultado de Pace (2013), estudando acabamento superficial em madeira de Corymbia citriodora sob intemperismo acelerado, verificou que após a aplicação da seladora e do stain essa madeira também escureceu, passando por fase de clareamento durante os períodos de intemperismo, voltando a escurecer ao final do teste.

Os espectros de refletância de cor de lâminas de madeira de teca em função do comprimento de onda para os períodos de intemperismo estudados podem ser vistos nas Figuras 1, 2a e 2b. Segundo Gonçalez (1993), os valores de refletância na região do visível permitem a caracterização da assinatura espectral de cada tratamento aplicado à madeira em estudo. Observa-se que os espectros de refletância dentro do visível (entre 360 e 750nm) têm comportamento linear e crescente para os três tratamentos.

O percentual de refletância para as testemunhas caiu sensivelmente até 24 horas, seguido de um aumento da refletância nos tempos seguintes, apresentando refletância máxima no tratamento de 384 horas.

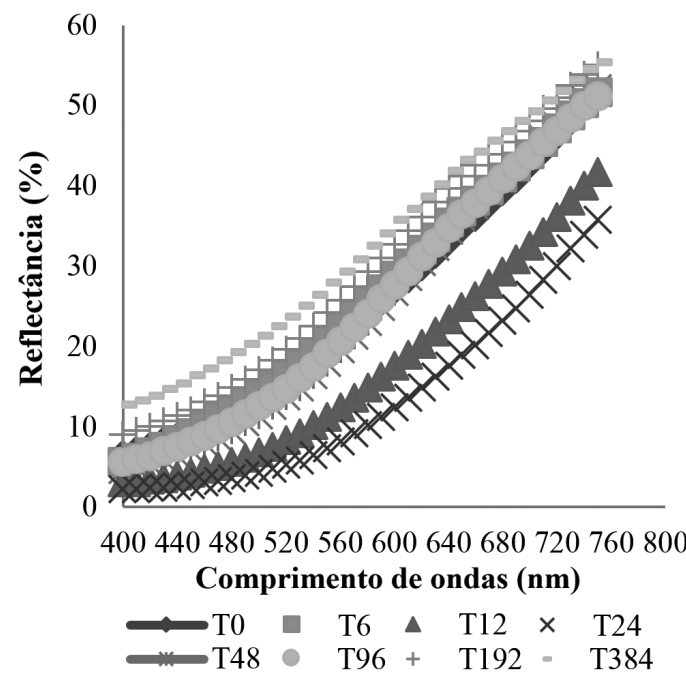

Figura 1. Espectros de refletância em função dos comprimentos de onda para as lâminas de teca (testemunhas) para os períodos de intemperismo estudados.

Figure 1. Spectral reflectances depending on the wavelengths for teak veneer (control) for weathering periods studied.
A Figura 2a representa o espectro de refletância considerando-se o produto de acabamento seladora. Observa-se que, até o tratamento 48 horas, os valores da refletância diminuem de forma similar nos comprimentos de onda. Depois desse tratamento, voltam a aumentar, apresentando refletância máxima no tratamento de 384 horas.

Já para o produto de acabamento stain, Figura $2 \mathrm{~b}$, os comprimentos de onda mostram curvas mais íngremes de refletância a partir de 560nm. Os valores de refletância diminuem de forma mais marcante até o tratamento 12 horas, voltando a aumentar levemente até o tratamento de 384 horas. No entanto, não se consegue atingir o valor máximo inicial, de antes dos períodos de tratamento.
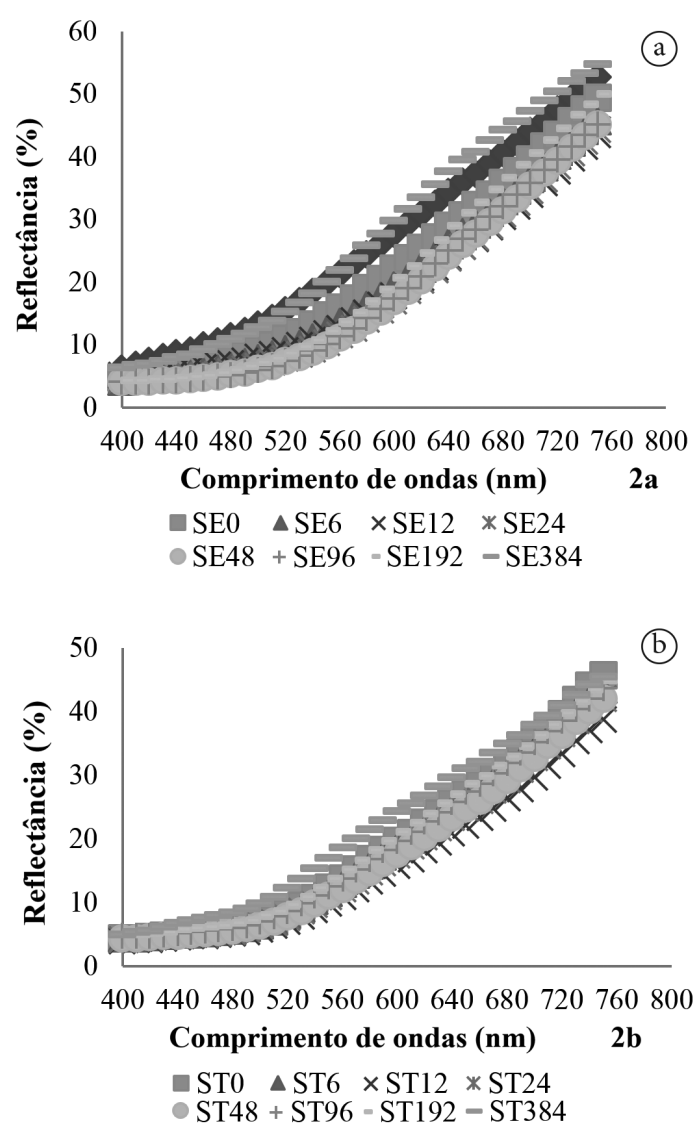

Figura 2. Espectros de refletância em função dos comprimentos de onda para as lâminas de teca acabadas com seladora (a) e stain (b) para os períodos de intemperismo estudados.

Figure 2. Spectral reflectances depending on the wavelengths to newly teak veneer with sealing (a) and stain (b) for weathering periods studied. 
Esses resultados são semelhantes aos de Pastore (2004), nos quais a irradiação ultravioleta na câmara de intemperismo mostrou tendência de provocar um escurecimento na cor da madeira de teca pela diminuição na intensidade da luz refletida. As testemunhas e o tratamento com seladora, ao final do processo, mostraram lâminas mais claras em relação às lâminas de antes do início dos períodos de intemperismo. Já o stain finalizou o processo com lâminas mais escuras do que as iniciais.

Temiz et al. (2007) e Dubey et al. (2010), investigando o envelhecimento acelerado em madeiras modificadas química e termicamente também chegaram a resultados em que a exposição a períodos de intemperismo produziram modificações na propriedade de cor da madeira de Pinus.

\section{CONCLUSÃO}

O processo de intemperismo em lâminas de madeira de teca buscou avaliar a resistência da cor dessa madeira, usando-se produtos de acabamento, em relação ao tempo de exposição à intempérie, gerando conhecimento do potencial de uso da espécie pelas indústrias que usam essa madeira como matéria-prima em sua produção.

Este estudo permitiu concluir que:

- As lâminas de madeira de teca sofrem alterações em sua cor com o passar do tempo, sendo essa alteração classificada de desprezível até muito apreciável, dependendo do tempo de exposição ao intemperismo e do produto de acabamento aplicado.

- Os períodos de intemperismo produziram alterações na cor das lâminas de Tectona grandis, detectadas pela variação dos parâmetros colorimétricos.

- A cor da madeira de teca natural é marromoliva, a qual escurece no início do intemperismo, voltando a clarear a partir do tratamento de 96 horas, tornando-se oliva amarelado de aspecto desgastado ao final de 384 horas de intemperismo.

- Os produtos de acabamento stain e seladora contribuíram para a qualidade das lâminas, por conservarem melhor as características de cor da madeira de teca submetida aos períodos de intemperismo acelerado.
- O stain apresentou maior eficiência na conservação da cor da madeira.

- A utilização de uma ferramenta mais precisa, como por exemplo, o NIR (infravermelho próximo), que auxiliaria na determinação dos constituintes químicos da madeira, poderia ajudar a compreender melhor o comportamento da madeira de teca e a mudança de sua cor sob o intemperismo, produzindo, assim, informações que poderiam orientar os fabricantes no desenvolvimento de produtos de acabamento mais resistentes.

\section{AGRADECIMENTOS}

Ao Instituto de Defesa Agropecuária do Estado de Mato Grosso - INDEA/MT, pela concessão de licença para qualificação profissional e ao Professor Ildeu Soares Martins pelo processamento de dados e estatística.

\section{STATUS DA SUBMISSÃO}

Recebido: 15 dez., 2014

Aceito: 2 nov., 2015

\section{AUTOR(ES) PARA CORRESPONDÊNCIA}

\section{Francis Lívio Corrêa Queiroz}

Departamento de Engenharia Florestal, Universidade de Brasília - UnB, Campus Universitário Darcy

Ribeiro, Via L3 Norte, s/n, Asa Norte, CP 04.357, CEP 70910-900, Brasília, DF, Brasil

e-mail: francislcq@hotmail.com

\section{REFERÊNCIAS}

American Society for Testing and Materials - ASTM. ASTM G 154: Standard practice for operating fluorescent light apparatus for uv exposure of nonmetallic materials. Philadelphia: ASTM; 2006.

Associação Brasileira dos Produtores de Florestas Plantadas - ABRAF. Anuário Estatístico da ABRAF 2013: ano base 2012. Brasília: ABRAF; 2013.

Bryce JM. Mechanical properties of Tanzania-grown teak. Moshi: Tanzania Forestry Department, Utility Section Moshi; 1966. Technical Note, n. 34.

Camargos JAA, Gonçalez JC. A colorimetria aplicada como instrumento na elaboração de uma tabela de cores de madeira. Brasil Florestal 2001; 71: 30-41. 
Camargos JAA. Colorimetria aplicada na elaboração de uma tabela de cores para madeiras tropicais [dissertação]. Brasília: Faculdade de Tecnologia, Universidade de Brasília; 1999.

Commission Internationale del'Eclairage - CIE. Colorimetry. Viena: CIE; 1976. Publication n. 15(2).

Costa RB, Chichorro JF, Resende MDV, Roa RAR, Cotta TR, Cezana DP. Variabilidade genética para o caráter germinação em matrizes de teca, no Município de alegre, ES. Pesquisa Floresta Brasileira. 2009; 59: 57-61.

Dubey MK, Pang S, Walker J. Color and dimensional stability of oil heat-treated radiata pinewood after accelerated UV weathering. Forest Products Journal 2010; 60(5): 453-459. http://dx.doi.org/10.13073/0015-7473-60.5.453.

Gonçalez JC. Caracterization technologique de quatre espèces peu connues de la forêt amazonienne: anatomie, chimie, couleur, propriétés physiques et mécaniques [tese]. Nancy: Ministère de l'Agriculture et de la Pêche; 1993.

Gonzaga AL. Madeira: uso e conservação. Brasília: IPHAN:MONUMENTA; 2006. Cadernos Técnicos, n. 6.

Gouveia FN. Aplicação de tratamentos térmicos para estabilização colorimétrica de madeiras tropicais [tese]. Brasília: Faculdade de Tecnologia, Universidade de Brasília; 2008.

Lima CM, Gonçalez JC, Costa TRV, Pereira RS, Lima JBM, Lima MSA. Comportamento da cor de lâminas de madeira de Balfourodendron riedelianum tratada com produtos de acabamento. Revista Árvore 2013; 37(2): 377-384. http:// dx.doi.org/10.1590/S0100-67622013000200020.

Lima IL, Pimentel MM, Garcia JN. Propriedades mecânicas e densidade aparente da madeira de Tectona grandis Linn. F. (Teca) em função do espaçamento e da posição radial na tora. Silva Lusitana 2011; 19(2): 221-232.
Lopes JO, Garcia RA, Nascimento AM, Latorraca JVF. Uniformização da cor da madeira jovem de teca pela termorretificação. Revista Árvore 2014; 38(3): 561-568. http://dx.doi.org/10.1590/S0100-67622014000300019.

Lopes JO. Uniformidade e estabilidade da cor da madeira termorretificada de Tectona grandis L. [dissertação]. Seropédica: Instituto de Florestas, Universidade Federal Rural do Rio de Janeiro; 2012.

Lukmandaru G. Variability in the natural termite resistance of plantation teak wood and its relations with wood extractive content and color properties. Journal of Forest Research 2011; 8(1): 17-31.

Pace JHC. Avaliação do acabamento superficial na madeira de Corymbia citriodora (hook) e Khaya ivorensis a. chev [monografia]. Seropédica: Instituto de Floresta. Universidade Federal Rural do Rio de Janeiro; 2013.

Pastore TCM. Estudos do efeito da radiação ultravioleta em madeiras por espectroscopias raman (FT-RAMAN), de refletância difusa no infravermelho (DRIFT) e no visível $\left(C I E-L^{*} a^{*} b^{\star}\right)$ [tese]. Brasília: Instituto de Química, Universidade de Brasília; 2004.

Teles RF. Ensaios não destrutivos para avaliar o desempenho de madeiras amazônicas tratadas quimicamente [tese]. Brasília: Faculdade de Tecnologia, Universidade de Brasília; 2014.

Temiz A, Terziev N, Eikenes M, Hafren J. Effect of accelerated weathering on surface chemistry of modified wood. Elsevier B.V. 2007; 253(12): 5355-5362.

Thulasidas PK, Bhat KM, Okuyama T. Heartwood colour variation in home garden teak (Tectona grandis) from wet and dry localities of Kerala, India. Journal of Tropical Forest Science 2006; 18(1): 51-54. 